\title{
Pituitary-adrenal mediation of bombesin-induced inhibition of gastrointestinal transit in rats
}

\author{
Debra E. Gmerek a and Alan Cowan ${ }^{\mathrm{b}}$ \\ Department of Pharmacology: "University of Michigan Medical School, Ann Arbor, MI 48109, and "Temple \\ University School of Medicine, Philadelphia, PA 19140, U.S.A.
}

(Received 14 June 1984; revised manuscript received 5 September 1984; accepted for publication

6 September 1984)

\begin{abstract}
Summary
Centrally administered bombesin (0.1-3.5 $\mu \mathrm{g}$, i.c.v.) inhibits gastrointestinal transit of a charcoal meal in a dose-related manner in rats. The roles of pituitary and adrenal glands in the mediation of this effect were assessed. The inhibition of gastrointestinal transit associated with bombesin $(0.5 \mu \mathrm{g}$. i.c.v. $)$ was prevented by either hypophysectomy or adrenalectomy. Bombesin-induced inhibition of gastrointestinal transit is therefore mediated through the pituitary-adrenal axis. This is in contrast to bombesin-induced scratching and inhibition of gastric acid secretion which are not markedly influenced by either hypophysectomy or adrenalectomy.
\end{abstract}

adrenalectomy; hypophysectomy; intracerebroventricular

\section{Introduction}

Bombesin is a brain-skin-gut peptide with pronounced effects on behavior [1,2], body temperature [3], blood glucose levels [4] and satiety [5]. In the present work we were particularly interested in the effects of intracerebroventricular (i.c.v.) bombesin on gastrointestinal function. In rats, centrally administered bombesin inhibits gastric acid secretion [6,7], stimulates gastric mucus production [8], inhibits gastric emptying [9] and small intestinal transit [9,10] and stimulates transit in the large bowel [9]. Interestingly, the effects of centrally administered bombesin appear to be mediated

Address all correspondence to: D.E. Gmerek, Ph.D., Department of Pharmacology, M6322 Medical Sciences Building I, University of Michigan Medical School, Ann Arbor, Michigan 48109-0010. U.S.A. Telephone: (313) 764-9123. 
through different mechanisms. For example, the stimulation of gastric mucus production is adrenal-dependent [8], whereas the inhibition of gastric acid secretion is adrenal-independent [6].

In this study, the question we addressed was: Is inhibition of gastrointestinal transit by i.c.v. bombesin dependent on intact pituitary and/or adrenal glands? We report here that both endocrine glands are required for the appearance of this effect. Thus, the inhibition of gastrointestinal transit by i.c.v. bombesin is apparently mediated through the pituitary-adrenal axis.

\section{Materials and Methods}

\section{Animals, surgery and housing}

Hypophysectomized, adrenalectomized and appropriate sham-operated male Sprague-Dawley albino rats were obtained from Zivic-Miller, 3 days following surgery. The hypophysectomized rats and their sham controls were given $5 \%(\mathrm{w} / \mathrm{v})$ glucose in their drinking water for 1 week; the adrenalectomized rats and corresponding controls received $0.9 \%(\mathrm{w} / \mathrm{v}) \mathrm{NaCl}$ in their drinking water continuously. These dietary supplements help to maintain the health of the operated animals. All rats were provided with food ad libitum. A standard timer-regulated light-dark cycle (light period from 7 am to $7 \mathrm{pm}$ ) was maintained.

Ten days after sham operation, adrenalectomy or hypophysectomy, when the rats weighed 180-200 g, they were each anesthetized with ketamine (Ketalar, Parke-Davis, $100 \mathrm{mg} / \mathrm{kg}$, i.p.) and stereotaxically implanted with a stainless steel cannula (Plastic Products Co.) directed towards the lateral cerebral ventricle, as described previously [2]. The rats were housed individually following cannulation. They were tested exactly 2 weeks after their original surgery.

Cannula placement was verified after experimentation by injecting methylene blue and observing the distribution of dye within the cerebroventricular system. All of the hypophysectomized rats tested had atrophied adrenal glands, an indication of successful hypophysectomy.

\section{Measurement of gastrointestinal transit}

Gastrointestinal transit was measured using the charcoal meal method described by Green [11]. Rats were starved overnight. Bombesin or saline was injected (i.c.v.) $20 \mathrm{~min}$ before the oral intubation of a meal consisting of charcoal, whole wheat flour and water in a $1: 2: 6(\mathrm{w} / \mathrm{v})$ ratio $(10 \mathrm{ml} / \mathrm{kg})$. The rats were killed by decapitation 35 min after the meal. The small intestine (gastroduodenal junction to cecum) was excised and lightly stretched along a meter-stick. The distance the marker travelled along the intestine and the total length of the small intestine were measured. Gastrointestinal transit was quantified as the percent of the small intestine traveled by the meal (\% GIT). Inhibition of transit was computed as follows: $\%$ inhibition = $100-(\%$ GIT after bombesin $\times 100) /(\%$ GIT after i.c.v. saline $)$. At least five rats were used for each dose. Statistical analyses of transit scores were performed using the analysis of variance followed by the Mann--Whitney U-test. The $A_{50}$ value (the 
dose which inhibits transit by $50 \%$ ) was estimated by linear regression analysis. Confidence limits $(95 \%)$ are shown in parentheses.

\section{Compound and injections}

Aliquots of synthetic bombesin (Boehringer Mannheim) were dissolved in saline daily as needed. Injections were given to hand-held conscious rats in volumes of 3-5 $\mu \mathrm{l}$, followed by a $0.5-1 \mu \mathrm{l}$ saline wash.

\section{Results}

Bombesin (0.1-3.5 $\mu$ g, i.c.v.) delayed gastrointestinal transit in normal (intact and untreated) rats in a dose-related manner (Fig. 1). The $A_{50}$ value for bombesin in normal intact animals was $0.26(0.12-0.53) \mu \mathrm{g}$.

A submaximal dose of bombesin $(0.5 \mu \mathrm{g}$, i.c.v.) was administered to hypophysectomized, adrenalectomized and appropriate sham-operated rats. The dietary supplements associated with sham operations appeared to: (a) increase gastrointestinal transit in general as shown by (sham + saline) compared with (normal + saline)

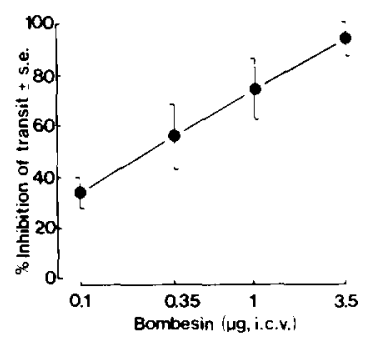

Fig. 1. The inhibition of gastrointestinal transit by bombesin in rats. All doses of bombesin inhibited transit significantly with $P=0.007$ at $0.1 \mu \mathrm{g}$ and $P \ll 0.001$ at $3.5 \mu \mathrm{g}$ (Mann-Whitney U-test).

\section{TABLE 1}

Effect of bombesin $(0.5 \mu \mathrm{g}$, i.c.v.) on gastrointestinal transit in hypophysectomized (HYPOX) or adrenalectomized (ADX) rats

\begin{tabular}{ll}
\hline Treatment & \% GIT \pm S.E.M. \\
\hline Normal ${ }^{\text {a }}+$ saline (i.c.v.) & $47.6 \pm 3.2$ \\
Sham HYPOX + saline (i.c.v.) & $60.8 \pm 3.7$ \\
Sham HYPOX + bombesin & $44.7 \pm 1.4$ \\
HYPOX + bombesin & $61.0 \pm 4.3^{\mathrm{c}}$ \\
Sham ADX + saline (i.c.v.) & $61.2 \pm 1.6$ \\
Sham ADX + bombesin & $41.5 \pm 7.6$ \\
ADX + bombesin & $62.3 \pm 2.8^{\mathrm{h}}$ \\
\hline
\end{tabular}

\% GIT, percent intestine travelled by charcoal meal.

a No dietary supplements.

h $P=0.007 .{ }^{\circ} P=0.0009$ compared to respective sham + bombesin controls (Mann-Whitney U-test). 
TABLE II

Influence of adrenalectomy (ADX) or hypophysectomy (HYPOX) on bombesin-induced effects

\begin{tabular}{llll}
\hline Effect & ADX & HYPOX & Reference \\
\hline $\begin{array}{l}\text { Inhibition of gastro- } \\
\text { intestinal transit }\end{array}$ & + & + & Present study \\
$\begin{array}{l}\text { Stimulation of gastric } \\
\text { mucus }\end{array}$ & + & & {$[8]$} \\
$\begin{array}{l}\text { Hyperglycemia } \\
\text { Inhibition of gastric }\end{array}$ & + & - & {$[4]$} \\
$\quad$ acid secretion & - & - & {$[6,7]$} \\
$\begin{array}{l}\text { Hypothermia } \\
\text { Grooming }\end{array}$ & - & - & {$[12,13]$} \\
$\begin{array}{l}\text { Elevation of mean } \\
\text { arterial pressure }\end{array}$ & - & - & {$[2]$} \\
Bradycardia & + & & {$[18]$} \\
\hline
\end{tabular}

$(+)$ indicates that the operation abolished the effect.

$(-)$ Indicates that the operation did not prevent the effect.

controls; and (b) decrease the effect of bombesin in sham-operated rats compared to normal (untreated) controls. However, bombesin still inhibited transit: \%GIT was significantly $(P<0.01)$ less after $0.5 \mu \mathrm{g}$ bombesin than after i.c.v. saline in the sham-operated rats. Gastrointestinal transit was not slowed by bombesin in either hypophysectomized or adrenalectomized animals (Table I). It should be noted that the amount of meal observed in the small intestine was less in bombesin-treated adrenalectomized rats than in (saline + adrenalectomy) controls, indicating that gastric emptying may still be inhibited by bombesin in adrenalectomized animals.

\section{Discussion}

Central administration of bombesin inhibits gastrointestinal transit in a potent, dose-related manner. The influence of a submaximal dose of bombesin was abolished after adrenalectomy or hypophysectomy. Thus, the slowing effect of bombesin on intestinal transit is mediated through the pituitary-adrenal axis.

The dietary supplements of isotonic saline in the adrenalectomized rats and glucose in the hypophysectomized rats were required to maintain the health of the animals. The sham-operated controls were similarly given the appropriate supplement in their drinking water. These conditions appeared to increase gastrointestinal transit of a charcoal meal compared with normal intact rats (without dietary supplements). Additionally, bombesin, while effective, was not as potent in inhibiting gastrointestinal transit in the sham groups as in normal (untreated) rats. The reason for this is not clear.

It is interesting to note that the various effects of bombesin are apparently mediated through different mechanisms (Table II). Bombesin-induced scratching 
behavior is not markedly affected by either adrenalectomy or hypophysectomy [2]. The same is true of bombesin-induced inhibition of gastric acid secretion [6,7] and hypothermia [12,13]. Adrenalectomy, but not hypophysectomy, prevents the hyperglycemia associated with intracisternal bombesin [4]. Bombesin-induced hyperglycemia is therefore postulated to occur as a result of increased sympathetic outflow [14]. Bombesin-induced stimulation of gastric mucus production is also adrenal-dependent [8]. It is not known if the stimulation of gastric mucus is dependent on intact pituitary glands.

Bombesin has been shown to inhibit gastric emptying in rats after both peripheral [15] and central administration [9]. In this study, we found that bombesin could delay the transit of an orally administered charcoal meal in a dose-related manner. High doses completely inhibit transit. However, bombesin maximally inhibits transit of an intraduodenally administered radiochromium marker by about only $60 \%$ $([9,10]$; personal observations). This verifies, indirectly, that inhibition of gastric emptying contributes substantially to the slowing effect of bombesin on gastrointestinal transit. It has been shown that vagotomy abolishes the ability of i.c.v. bombesin to delay gastric emptying [9]. Our observation that bombesin-induced inhibition of gastric emptying appears to be retained in adrenalectomized rats is in concordance with vagal mediation of this effect. However, further studies are required for quantification of this phenomenon.

The exact mechanism by which i.c.v. bombesin inhibits gastrointestinal transit is not clear. The requirement of intact pituitary and adrenal glands indicates that the pituitary-adrenal axis is involved. This in turn suggests that bombesin might be directly stimulating the release of a pituitary hormone which would then act on the adrenal to stimulate the release of a substance which in turn inhibits gastrointestinal transit. Our first thought was that beta-endorphin might be involved, especially since opioids are also known to inhibit gastrointestinal transit. However, the opiate antagonist naltrexone does not attenuate the actions of i.c.v. bombesin on intestinal transit (Gmerek and Cowan, unpublished data). Therefore, the endogenous opioids are not involved. It is not known if the release of adrenocorticotrophic hormone (ACTH) would result in an inhibition of gastrointestinal transit. Glucocorticoids released by ACTH have gastrointestinal effects [16], however. An indirect action of bombesin on the pituitary is also possible. It has been suggested that bombesin acts centrally to increase sympathetic outflow which induces a release of epinephrine from the adrenals [14]. Other hormones released from the adrenals may feed back to the pituitary; feedback regulation being required for the antitransit effect of bombesin. Bombesin has been said to be "one of the most effective and polyvalent "releasing factors' so far known" [17]. It is yet to be determined which of these, if any, is involved in the slowing of gastrointestinal transit observed following bombesin administration.

\section{Acknowledgement}

This work was supported by NIH Grant BRSG SO7 RR05417. 


\section{References}

1 Kulkosky, P.J.. Gibbs, J. and Smith, G.P., Behavioral effects of bombesin administration in rats. Physiol. Behav., 28 (1982) 505-512.

2 Gmerek, D.E. and Cowan, A., Studies on bombesin-induced grooming in rats. Peptides. 4 (1983) 907-913.

3 Brown, M., Rivier, J. and Vale, W., Bombesin: potent effects on thermoregulation in the rat. Science. 196 (1977) 998-1000.

4 Brown, M.R., Rivier, J. and Vale, W.W., Bombesin affects the central nervous system to produce hyperglycemia in rats, Life Sci., 21 (1977) 1729-1734.

5 Gibbs, J., Kulkosky. P.J. and Smith, G.P., Effects of peripheral and central bombesin on feeding behavior in rats, Peptides, 2 (Suppl. 2) (1981) 179-183.

6 Taché, Y., Vale, W., Rivier, J. and Brown. M.. Brain regulation of gastric secretion: influence of neuropeptides, Proc. Natl. Acad. Sci. USA. 77 (1980) 5515-5519.

7 Taché, Y. and Collu, R., CNS mediated inhibition of gastric secretion by bombesin: independence from interaction with brain catecholaminergic, and serotoninergic pathways and pituitary hormones. Regul. Peptides, 3 (1982) 51-59.

8 Taché, Y.. Bombesin: central nervous system action to increase gastric mucus in rats. Gastroenterology, 83 (1982) 75-80.

9 Porreca, F. and Burks, T.F., Centrally administered bombesin affects gastric emptying and small and large bowel transit in the rat, Gastroenterology, 85 (1983) 313-317.

10 Gmerek, D.E., Ryan, J.P. and Cowan. A., Cross-tolerance between morphine- and bombesin-induced inhibition of small intestinal transit in rats. Fed. Proc., 42 (1983) 346.

11 Green. A.F., Comparative effects of analgesics on pain threshold, respiratory frequency and gastrointestinal propulsion, Br. J. Pharmacol. Chemother., 14 (1959) 26-34.

12 Rasler, F.E., Bombesin produces hypothermia in hypophysectomized rats, Life Sci.. 32 (1983) 2503-2507.

13 Hawkins, M.F. and Avery, D.D., Effects of centrally-administered bombesin and adrenalectomy on behavioral thermoregulation and locomotor activity, Neuropharmacology, 22 (1983) 1249-1255.

14 Brown, M., Taché, Y. and Fisher, D., Central nervous system action of bombesin: mechanism to induce hyperglycemia, Endocrinology, 105 (1979) 660-665.

15 Scarpignato, C. and Bertaccini, G., Bombesin delays gastric emptying in the rat, Digestion, 21 (1981) $104-106$.

16 Gass, G. and Kaplan, C. (Eds.), CRC Handbook of Endocrinology, CRC Press, Boca Raton, Florida, 1982, pp. 212-214.

17 Bertaccini, G., Peptides: candidate hormones. In G. Bertaccini (Ed.), Mediators and Drugs in Gastrointestinal Motility 11, Springer-Verlag, New York. 1982. pp. 124-135.

18 Fisher, L.A. and Brown, M.R., Bombesin-induced stimulation of cardiac parasympathetic innervations, Regul. Peptides, 8 (1984) 335-343. 